\title{
A função das emprêsas internacionais na indústria automotriz da América Latina
}

\author{
Russell Martin Moore *
}

1. Introdução. 2. Caracteristicas da Indústria Automotriz Mundial. 3. A Indústria Automotriz da América Latina. 4. Análise do Caso Brasileiro. 5. Conclusöes: Recomendações Politicas.

Os desejos dos governos latino-americanos de estimular o desenvolvimento social, econômico e político impõem a necessidade de fazer uma dificil escolha entre aspectos contraditórios da meta geral de desenvolvimento. Como exemplo déste fato, pode-se citar a oposição entre o objetivo de promover uma mudança qualitativa e quantitativa nos bens e serviços produzidos pelas economias nacionais, e o desejo de aumentar o grau de independência nacional, definida como a consecução da autonomia total na adoção de decisões em cada setor econômico. Essas contradições procedem das repercussões tecnológicas da produção de bens e serviços modernos. Para produzir éstes bens de maneira eficiente, é imprescindível respeitar suas relações técnicas básicas de produção. Isto implica freqüentemente o investimento de um grande montante de capital na invenção e aperfeiçoamento de novos produtos, de novos processos de produção, além de grandes pe-

- Latin Amerlcan Teaching Fellow, The Fletcher School of Law and Diplomacy. Universidade de Tufts, destacado como professor visitante de Economia Internacional, na Escola de AdmInistraçăo de Empresas de São Paulo, da Fundação Getúllo Vargas. Este trabalho se basela em informaçőes obtidas de 120 entrevistas a funcionários de govêrno de associaçōes industriais e a executivos de emprêsas do Brasil, Chlle, Urugual, Canadá e Estados Unidos. Além disso o autor estêve vinculado durante vários anos com duas flrmas internacionais. uma das quais é fornecedora da indústrla automobilistica e a outra produtora, participando ambas ativamente na in dústria automotriz latino-americana.

R. Adm. Emp., Rlo de Janeiro, ríodos de gestação e do estabelecimento de extensas rêdes de distribuição. O pré-requisito básico, no entanto, é a capacidade da organização de acumular a grande variedade de recursos físicos e humanos necessários para produzir o artigo desejado. Freqüentemente, necessita-se de um alto volume de produção para permitir uma utilização efetiva désses insumos técnicos e de organização, a fim de reduzir, ao mínimo, os custos unitários do produto final.

A capacidade de organização das sociedades latino-americanas procede geralmente de quatro fontes: o govêrno, o setor privado nacional, o setor privado estrangeiro e potencialmente as emprêsas regionais multinacionais. Essa capacidade de organização, definida em têrmos gerais, necessária para produzir muitos bens modernos, sómente a possuem, atualmente, de forma desenvolvida, firmas internacionais. A escolha de qualquer outra opção como principal agente de produção ao invés da emprêsa internacional talvez envolva custos, a longo e médio prazo, muito mais altos. Porém, a dependência de firmas internacionais para produzir os bens e serviços necessários talvez poderá implicar o custo político e social de aceitar um grau relativamente elevado de interdependência internacional, $e$ isto parece opor-se a outra meta do desenvolvimento, a de aumentar a independência nacional.

11(1): $53-64$

Jan./Mar.

1971 
gráfico 1

Oposiçăo entre os Fins do Desenvolvimento Nacional

- a Forma de Atingir estes Fins

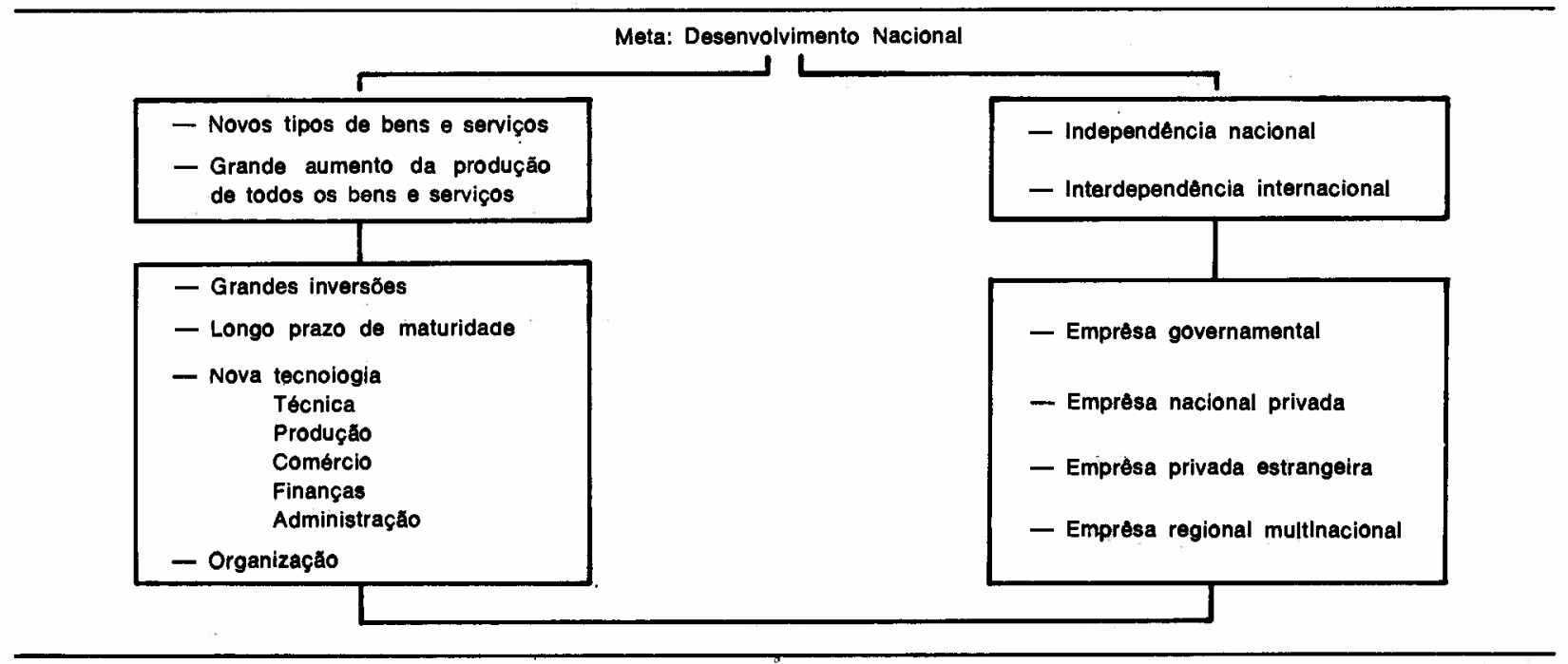

Um acôrdo freqüentemente adotado consiste em utilizar as firmas internacionais, porém mantendo o contrôle nacional de decisão, separando o mercado nacional do mercado internacional. Infelizmente, esta política muitas vêzes conduz à violação de um dos requisitos da produtividade: a necessidade de produzir um volume elevado para obter os lucros das economias de escala em se tratando de técnicas, produção, comércio e financiamento.

Neste trabalho, sugere-se que a aceitação de um maior grau de interdependência no campo político com respeito a cada setor, acrescentará talvez em última análise a independência geral dos diversos países no sentido de permitir-lhes gerar os recursos necessários para aumentar o bem-estar de sua população.

O tópico seguinte sóbre a indústria automotriz da América Latina ilustra o ponto de vista exposto.

\section{Caracteristicas da indústria automotriz mundial}

Uma caracteristica notável da indústria automotriz mundial é a sua crescente inter- dependência internacional. A produção de veículos nas economias de mercado do ocidente encontra-se concentrada em quinze emprêsas que fornecem aproximadamente $90 \%$ da produção total. Nos países industrializados é cada vez mais comum o deslocamento internacional de produtos, de téenicas de produção, recursos financeiros e talento empresarial. Neste mercado internacional a concorréncia parece estar impondo um grau sempre maior de concentração industrial, e alguns observadores sugerem que no futuro imediato as emprêsas de produção anual inferior a dois milhões de unidades dificilmente sobreviverão. Isto significa que qualquer país - incluindo um pais com a capacidade tecnológica da Uniāo Soviética - terá que aceitar certo grau de colaboração das emprêsas internacionais dominantes para possuir uma indústria automotriz a um custo razoável.

Outra característica importante da indústria automotriz é a grande dependência que os produtores têm em relação a peças e acessórios. Do ponto de vista da eficiéncia, á mais conveniente ao produtor recorrer a fornecedores estranhos à emprêsa (que utilizam as economias de escala para abastecer 
tôda a indústria) do que êle próprio produzir. Os fornecedores especializados não só gozam de vantagens no que se refere ao custo de produção, mas também se preocupam de certo modo com o aperfeiçoamento técnico de seu produto. A maioria dos fornecedores independentes são emprêsas relativamente pequenas, mas alguns dêles bastante diversificados, que se especializam em peças mais complexas, chegaram a transformar-se em gigantescas emprêsas internacionais, como a Borg Warner, Joseph Lucas, Eaton, Robert Bosch, Nort American Rockwell, TRW, Clark, Zahnradfabrik Friedrichschafen e Dana, que figuram entre os mais importantes.

Os produtores mantêm um vínculo muito estreito com os fornecedores de peças pelo fato de necessitar-se da perfeita coordenação para produzir em série, com êxito, produtos tão complexos como veículos motorizados. Entretanto, um dos fatôres que parece contribuir para a eficiência na produção de veículos é a forte concorrência que existe entre os produtores e os fornecedores independentes.

A ameaça da integração vertical obriga aos fornecedores baixarem constantemente seus custos e melhorarem seu produto. Além disso, os produtores sempre desejam ter, pelo menos, duas fontes de fornecimento para beneficiar-se da rivalidade entre elas (ou da rivalidade entre os fornecedores $e$ as divisões da emprêsa), a fim de assegurarem-se para evitar interrupções no fornecimento. Entre os produtores e os fornecedores existe uma grande dependência mútua, mas nessa relação nos paises industrializados dominam claramente os primeiros.

\section{A indústria automotriz da América Latina}

Nos últimos quinze anos vários países latino-americanos adotaram medidas para estimular o desenvolvimento da indústria automotriz nacional. São três os motivos básicos desta política: 1 . as restrições da balança de pagamentos que freqüentemente impedem que as importações de veículos se mantenham a um nivel suficiente para suprir as necessidades de transporte da crescente economia; 2. supõe-se que a indústria automobilística favoreça o desenvolvimento através de seus efeitos de encadeamento anteriores e posteriores sôbre a economia; e 3 . incentiva-se a produção nacional para reduzir a dependência econômica e política em relação aos países industrializados. Para induzir a indústria a transportar-se de seus centros tradicionais na Europa e América do Norte aplicaram-se políticas de substituição de importações que aceitam explicitamente os altos custos a curto prazo das indústrias nascentes a fim de granjear os benefícios a longo prazo das mudanças estruturais nas diversas economias da América Latina.

As emprêsas que participam da indústria automotriz da América Latina formam um grupo misto de emprêsas internacionais e nacionais, embora em alguns casos se incluíram algumas emprêsas de propriedade do govêrno. As firmas internacionais foram adquirindo um crescente predomínio no setor da indústria que elabora o produto final, de tal maneira que as emprèsas nacionais predominam no setor fornecedor de peças. A medida que a indústria alcançou a maturidade, especialmente na Argentina, Brasil e México, houve uma tendéncia a eliminar-se da área produtora as firmas nacionais $e$ as firmas mistas nacionais e estrangeiras, mais débeis devido a sua falta de recursos técnicos, financeiros $\theta$ administrativos. $O$ fato de recorrerse aos investidores estrangeiros para que forneçam grande parte da capacidade administrativa para a indústria automotriz da América Latina permitiu conservar os veículos com a indústria mundial no que se refere às finanças, às técnicas e à organização geral, mas o estabelecimento de barreiras protetoras reduziu ao mínimo a coordenação da produção e do comércio com o mundo exterior.

\subsection{Contribuições e Problemas de Indústria}


Os programas de substituição de importação de automóveis estimularam com enorme éxito as atividades manufatureiras. Alcançaram-se niveis apreciáveis de produção e emprêgo, e é evidente que aumentaram os recursos técnicos e empresariais da economia nos diversos países. Entretanto, persistem quatro problemas vinculados entre si em tôrno das atividades das indústrias: os veículos produzidos nos países latino-americanos continuam sendo entre 30 a $150 \%$ mais caros que os veículos similares produzidos nos paises industrializados; ${ }^{1}$ a variedade de que o consumidor pode dispor é relativamente limitada; a qualidade do produto é as vêzes inferior à do mercado internacional; e excetuando-se aquilo que não é gasto com importações, os ganhos no setor externo são práticamente nulos. Para elevar ao máximo os lucros da fabricação de veículos automotores, é necessário criar novas políticas para resolver os demais problemas, que englobem uma esfera mais ampla que as concepções originais em que se basearam os programas de substituição de importações. A pergunta que cabe fazer é: como criar um quadro juridico que encaminhe a indústria de forma progressiva e sustentada desde a infáncia $\theta$ a adolescência até a maturidade

\subsection{Exame dos Problemas Básicos}

Parecem existir duas razões fundamentais pelas quais são comparativamente altos os custos de produção dos veículos fabricados na América Latina. Primeiramente devido ao tamanho limitado de cada mercado nacional separado, e ao grande número de produtores que existe em cada mercado, não podem existir as condições básicas de efici-

\footnotetext{
1 Ver Baranson, Jack. Automotlve Industries in developing countries (informe Inédito do Banco Mundial n? EC-162, 32 de malo de 1968, p. 29-31); onde aparecem exemplos dos custos comparados da produçăo de velculos na Argentina, Brasil, México e Estados Unidos.

2 Ver por exemplo o capitulo 4 em Maxcy, George Silberson, Aubrey. The motor industry. Cambridge Studies in industry, Londres, George Allen and Unwin. 1959
}

encia para cada produtor. A maioria dos estudos demonstra que o volume ótimo de produção para a indústria automotriz é pelo menos 100.000 unidades anuais. ${ }^{2}$

Em tôda América Latina só há um produtor, a Volkswagen do Brasil, que conseguiu produzir mais. $O$ volume médio dos demais produtores importantes da Argentina e México está em tórno de 25.000 e no Brasil cêrca de 40.000 unidades, sendo que êste volume engloba vários tipos de veículos. As taxas prováveis de crescimento do mercado indicam que transcorrerão de cinco a dez anos, antes que os novos produtores possam elevar o seu volume até alcançar o nível ótimo provável, a menos que se produza também um volume apreciável de exportações de peças e de veículos acabados.

Em segundo lugar, a tendência de manter cada mercado nacional isolado atrás de barreiras protetoras tendeu a limitar a concorrência. $O$ aumento da concorrência entre os produtores, os fornecedores de peças, e os produtores e fornecedores teria o saudável efeito de eliminar as possíveis utilidades monopolistas $\theta$ de obrigar 0 aperfeiçoamento de qualidade do produto. $O$ aumento controlado das importações poderia estimular de maneira eficaz o aumento da competição.

Serão muito graves as conseqüências para os paises da América Latina se os governos não resolverem éstes problemas. Se não conseguirem aumentar a produção da indústria automotriz, o equipamento de transporte, que tem a mais alta prioridade nos programas de desenvolvimento, continuará sendo muito caro; continuarão concedendo recursos escassos à indústria automotriz que é relativamente ineficiente, prejudicando a outros setores prioritários; a a indústria moderna mais importante continuará dando uma contribuição quase nula em divisas.

A chave para resolver os problemas da indústria automotriz da América Latina parece ser a aplicaçăo de políticas que permitam às indústrias nacionais alcançarem um grau razoável de integração nos mercados in- 
ternacionais. Nenhuma indústria automotriz da América Latina está preparada para competir no mercado internacional: os custos continuam sendo muito elevados, continua sendo necessário melhorar a qualidade e criar produtos vendáveis. Como medida provisória para superar esta etapa da adolescência, a criação de um mercado regional ou de vários mercados sub-regionais na América Latina ofereceria boas possibilidades. Mas o labirinto de medidas que protegem direta $e$ indiretamente a indústria automotriz de todos os palses da América Latina não permite alcançar a auténtica integração regional, apesar de haver sido apoiada verbalmente por elementos dos diversos governos, por porta-vozes do setor privado e representantes dos órgãos internacionais nos últimos 15 anos. Estabeleceramse muitos incentivos à exportação, mas não se concedeu o tratamento reciproco que contribuiria para estimular bastante as importações regionais. Embora todos os países desejem exportar, como ilustra o fato de se mostrarem contrários a permitir as importaçōes sôbre bases preferenciais, o intercâmbio regional atual não teve repercussões favoráveis sóbre os custos. A integração regional deveria basear-se na especialização internacional, nas economias de escala, na redução de custos e preços, através do que o aumento da produção seria maior do que se não houvesse especializaçăo. A longo prazo, a indústria automotriz faria mais inversões - criaria mais emprégo nos países, se fósse possível operar em condiçőes mais eficientes de custo.

Uma das razões pela qual não prosperou a idéia de criar um mercado regional foi a dificuldade para desentranhar os complexos interesses dos governos, das emprêsas nacionais $\theta$ internacionais. $A$ análise que se faz para a continuação da indústria automotriz no Brasil ilustrará a forma pela qual estes interésses e objetivos opostos criam obstáculos para a integração desta indústria do Brasil com uma indústria regional.

\section{Análise do caso brasilleiro}

Algumas das muitas barreiras para 0 comércio regional de produtos da indústria automotriz têm origem em fatóres gerais do meio ambiente: falta de uma infra-estrutura de transporte, inflação endémica, diferentes taxas de cambio, $\theta$ incertezas politicas periódicas. Entretanto, o autor cré que estes problemas sejam secundários, e que a principal barreira no comércio inter-regional reside na complexa natureza das instituições que maior Influência têm no estabelecimento de um mercado regional: os governos, os produtores e os fornecedores.

A política de substituição de importações de automóveis teve sob vários pontos de vista um grande éxito no Brasil. Pode-se esperar que em 1970 o volume passe de 400.000 unidades, o que permitirá à indústria brasileira continuar ocupando o 11 ! lugar entre os paises produtores com economia de mercado. Alguns observadores otimistas crêem que a indústria alcançará um volume de 1.000 .000 unidades em 1980, e que não há possibilidades de saturação do mercado. 0 conteúdo nacional dos automóveis produzidos no Brasil aproxima-se dos $100 \%$, calculado sôbre a base do péso. As principais criticas formuladas contra a indústria brasileira são que os preços dos veículos continuam sendo mals elevados que os do mercado mundial, e que o volume de exportaçōes é extremamente limitado.

O govêrno estabeleceu diversos incentivos para todos os exportadores de produtos industriais, incluindo os da indústria automotriz, mas até a elaboração déste trabalho houve pouca reação por parte dos produtores e dos fornecedores de peças. ${ }^{3}$ A principal barreira para o aumento das exportaçōes da indústria automotriz brasileira aos paises industrlalizados está em que os custos (e às

3 Por exemplo, em 1969 edmente se exportaram 68 veículos de uma produçto de 350.000 unidades. E interessante assinalar que todas as companhlas entrevlstadas mostraram muito interesso em exportar (sem mencionar restriçסes quanto ao mercado). 
vêzes a qualidade) năo cumprem ò requisitos para competir nos mercados internacionais. As exportações do Brasil para outros países da América Latina não atingiram um volume de importancia, porque a legislação vigente nestes paises no que se refere ao in- " dice de nacionalização impede a importação de veículos ou de assessórios de qualquer espécie. Se se tornassem mais flexíveis as disposiçōes sôbre 0 indice de nacionalização, dando preferéncia aos produtos automotrizes de outros países da América Latina, - equiparando a legislação vigente em muitos dêstes países - abririam importantes perspectivas de intercambio especialmente com a Argentina, Venezuela e México.

\subsection{O Produtor}

Os produtores tém sido os mais convictos partidários da criação de um mercado regional para a indústria automotriz, mas a sua posição tem sido relativamente precária por trés motivos: primeiro, as companhias concorrem entre si, de acórdo com seus in-

Tabela 1: Fabricantes de Vefculos na Argentina - no Brasil, 1969

(Milhares de unidades)

\begin{tabular}{|c|c|c|c|}
\hline Emprêsa & Argentina & Brasil & Total \\
\hline $\begin{array}{l}\text { Volkswagen } \\
\text { Ford-Willys } \\
\text { General Motors } \\
\text { Fiat - Renault } \\
\text { IKA - Rensiler } \\
\text { Chrysier } \\
\text { Mercedes-Benz } \\
\text { SAFRAR (Peugeot) } \\
\text { Clitroën } \\
\text { l. M. E. } \\
\text { i. A. Santa Fe (DKW } \\
\text { FNM } \\
\text { Scania Vabis } \\
\text { Toyota } \\
\text { Magirus Deutz } \\
\text { Puma } \\
\text { DECA i. C. S. A. }\end{array}$ & $\begin{array}{r}36.1 \\
30.4 \\
49.5 \\
34.3 \\
17.9 \\
5.8 \\
20.6 \\
15.3 \\
7.7 \\
1.0 \\
= \\
= \\
= \\
0.1\end{array}$ & $\begin{array}{r}178.2 \\
88.8 \\
52.8 \\
= \\
11.8 \\
17.3 \\
= \\
= \\
2.2 \\
1.0 \\
0.9 \\
0.4 \\
0.3 \\
\end{array}$ & $\begin{array}{r}178.2 \\
124.9 \\
83.2 \\
49.5 \\
34.3 \\
29.7 \\
23.1 \\
20.6 \\
15.3 \\
7.7 \\
1.0 \\
2.2 \\
1.0 \\
0.9 \\
0.4 \\
0.3 \\
0.1\end{array}$ \\
\hline & 18.7 & 3.7 & 72.4 \\
\hline
\end{tabular}

Fontes: Associaçăo de Fábricas de Automotores, Argentina. Informe Estatistico n? 351, 14 de janeiro de 1970.

Brasil, Noticias de ANFAVEA, $n ? 137$, janeiro de 1970. terésses com respeito à integração; segundo, os fato̊res de organização interna tenderam a limitar a eficácia dos esforços para promover a integração; $\theta$ terceiro, a renúncia dos governos a aceitar a regionalização, que em alguns casos aumentam, como reação, os argumentos dos produtores, limitou os resultados práticos das propostas dos produtores.

A tabela 1 ilustra os conflitos potenciais que podem existir entre os produtores em relação à possivel integração das indústrias automotrizes da Argentina e Brasil. A Volkswagen do Brasil estaria em uma posição especial do ponto de vista de sua produção anual. Os outros produtores pirncipais, Ford, General Motrs, Fiat, Renault, Peugeot e Citroën produzem um volume semelhante que flutua de 15.000 a 30.000 unidades por tipo de veículo. 4 E provável que as suas estruturas de custo sejam bastante semelhantes entre si, ainda que difiram consideràvelmente com respeito à Volkswagen, emprêsa que parece ter enormes vantagens potenciais em matéria de custos, devido as economias internas. A integraçăo total das indústrias da Argentina e Brasil, que permitiria o livre intercâmbio de veículos e peças, modificaria o panorama. A Ford $\theta$ a General Motors, $\theta$ até mesmo a Chrysler e a Mercedes Benz potencialmente se beneficiariam mais das possibilidades de racionalizar suas instalações que atualmente se duplicam. A Fiat, a Renault, e a Citroën teriam acesso a novos mercados e novas fontes de financiamento, mas nāo teriam a mesma possibilidade de beneficiar-se com a racionalização interna, porque só têm fábricas em um país. Além disso, teriam que fazer frente à nova competição da Volkwagen, que provàvelmente goza da vantagem de ter uma estrutura interna de custo muito mais favorável. Uma amplicação do mercado talvez levasse um concorrente potencialmente forte,

4 Considera-se que a Mercedes Benz constltui um caso especial porque concentra sua produção na fabricação mais de velculos comerciais médios e pesados que em velculos para passageiros e velculos comerciais médios e leves. 
como a Toyota, que atualmente não tem mais que uma participação simbólica, a entrar seriamente no mercado.

Apesar destas considerações sôbre a concorréncia, a politica aplicada pelos produtores na Argentina e no Brasil parece ter evoluido no sentido de encontrar alguma fórmula para iniciar a integraçăo do mercado. Esta tendéncia se fortificou à medida que as firmas mais débeis como a Vemag e a Willys do Brasil se viram obrigadas a fundirem-se com emprésas mais poderosas, capazes de coordenar suas operaçర̃es internacionais. Entretanto, a integração continua sendo apoiada com igual entusiasmo pelos diversos produtores. O mercado regional lhes ofereceria genèricamente as seguintes vantagens: 1 . permitiria evitar a duplicação das inversões; 2. ampliaria as suas linhas de modelos; 3. ofereceria acesso a fontes de abastecimento mais seguras $\theta$ abundantes; 4 . baixaria os custos - melhoraria a qualidade; 5. aumentaria a penetração no mercado e o volume de vendas; 6. aumentaria eventualmente os lucros. A integração traz consigo mudanças e riscos. Sòmente as organizaçōes que maior confianca têm em si mesmas acolherăo bem os beneficios potenciais que traria a perturbação da atual estabilidade na concorréncia.

O progresso da integração regional viuse retardado por fatôres internos das próprias companhias internacionais: a coordenação das oficinas matrizes sofriam de algumas deficiências, de modo que os administradores nos diversos paises nāo deram maior prioridade às possibilidades de integração. E compreensivel que se tenha prestado menor atenção aos benefícios potenciais a longo prazo da integração que aos problemas urgentes de curto prazo relacionados com 0 cumprimento das disposições governamentais que exigem elevar constantemente 0 indice de nacionalização. A coordenação das atividades regionais tem sido relativamente limitada, devido em parte à pressão das circunstâncias que provocaram a duplicação geral das instalações na região. E o que é mais importante, ainda que se produzam veículos semelhantes nos vários países da América Latina, há nêles muitos detalhes diferentes, $O$ que torna difícil o comércio de peças sem uma coordenação técnica adicional.

A participação nas reuniőes setoriais regionais e de negociaçன̃es entre os paises sóbre aspectos do comércio regional foi considerada em alguns casos mais como um problema de relações públicas que um processo que poderá mudar bàsicamente a estrutura automotriz da América Latina. Sòmente nos últimos anos empenharam-se em conceder os recursos financeiros e elementos de planejamento e coordenação adequados à produção regional, mas êstes continuam sendo insuficientes. As emprêsas principais que tomam as decisões não examinaram sistemàticamente os problemas $e$ as possibilidades de um mercado regional. Alguns dos objetivos básicos da política de desenvolvimento do Brasil são: 1) elevar ao máximo o emprêgo, 2) elevar ao máximo a inversão, 3) aumentar o poder do Estado nas decisões econômicas, e 4) fortalecer o setor privado brasileiro. A primeira vista, a integração regional reduziria a taxa de aumento do emprêgo e da inversão, da autonomia nacional e poria em perigo o setor privado nacional. Sòmente uma prova muito concludente da integraçāo contribui para acrescentar o emprêgo, para aumentar a produção, fortalecer o setor nacional privado e poderia influir para que se aceitasse o inevitável aumento da interdependência na formulação da política para o setor da indústria automotriz.

Entretanto, os diversos acôrdos de complementação e as disposiçōes legais vigentes nos diversos paises da América Latina sôbre peças de origem nacional ou procedentes de paises da ALALC, 5 no lugar de criar ações concretas $\theta$ induzir à análise económica, foram apresentados ao govêrno pe-

5 Nota do tradutor: Vinculados com o cumprimento dos requisitos legais vigentes em diversos paises $d a$ América Latina que estabelecem a obrigatoriedade de que uma determinada porcentagem do valor ou o pêso dos velculos montados no pais seja de origem nacional 
los produtores mais como um compromisso em aberto.

Apesar da moderada acolhida que tem a regionalização nos produtores, observa-se certa falta de espírito inovador para encarar os problemas e preocupações especiais de indole social e política. Tanto os governos como os fornecedores nacionais de peças têm grandes reservas com respeito aos efeitos da criação de um mercado regional no grau de integração vertical dos produtores e com respeito à tendéncia da desnacionalização da indústria automotriz.

Neste sentido, um dos problemas fundamentais parece ser a rigidez dos produtores controlados por interêsses estrangeiros no que se refere à participação local no seu capital.

\subsection{Os Fornecedores}

Ainda que no Brasil existam dez produtores que dăo emprégo a 65.000 pessoas, existem mais de 1.500 fornecedores na indústria que empregam aproximadamente 150.000 trabalhadores. Estes fornecedores podem dividir-se em trés grupos: emprésas controladas por interêsses estrangeiros, pequenas emprêsas controladas localmente e emprêsas médias e grandes controladas localmente. ${ }^{6}$

A maioria dos fornecedores internacionais têm fábricas no Brasil que produzem pelo menos uma de suas principais linhas de produto. Estas emprésas tiveram, relativamente, pouca participação ativa na determinação da política do setor fornecedor em relação à integração regional, ainda que em geral se mostrem favoráveis a ela. As firmas fornecedoras controladas por interêsses estrangeiros não consideram que a integração regional seja uma ameaça porque: 1 . têm fábricas em tôda América Latina, 2. como é mais importante para elas manter boas relaçōes com os produtores nos paises industrializados, pre-

- Ver Telxelra Vieira, Dorlval. Pequenas a módias Indústrias de autopeças. Săo Paulo, Programa Delft, 1967. ferem não expor-se a risco, opondo resistência à integração na América Latina, 3. as perdas numa linha de produção devido ao aumento da pressão competitiva poderiam ser compensadas, introduzindo novos produtos acabados que atualmente não se fabricam na América Latina, e 4. essas emprésas têm recursos suficientes para nāo temer a concorrência. Entretanto, apesar do apoio geral à integração regional, os fornecedores estrangeiros nāo a estimulam efetivamente. Suas inversões já se encontram em alguns casos duplicadas na regiăo, não há coordenação em suas atividades e, o que é mais importante, algumas vêzes assinaram acôrdos em matéria de autorizações e de emprésas mistas em diferentes paises que os obrigam a continuar aceitando a divisão do mercado regional em compartimentos separados.

O grande número de pequenos fornecedores controlados por interésses nacionais tendem a ser contrários às propostas de regionalização da indústria automobilistica devido ao fato de temerem a concorrência e de não perceberem suas possiveis vantagens. Estas emprêsas possuem recursos técnicos, financeiros e administrativos limitados, e têm pouco interêsse por questōes mais gerais como a integração regional. Seu capital e sua tecnologia freqüentemente têm sido proporcionados pelos produtores, que necessitavam com urgência encontrar fontes locais de financiamento. Muitos dos problemas de qualidade dos produtos fabricados no Brasil podem ser atribuidos a deficiências dêstes fornecedores. Contudo, os dirigentes do setor acreditam que é muito importante não aceitar um nôvo quadro de comércio exterior que criaria dificuldades para as pequenas companhias controladas localmente.

o grupo que participa mais ativamente na determinação da política do setor fornecedor é formado pelas emprêsas grandes e médias de propriedade nacional. $O$ rendimento destas emprêsas costuma ser excelente do ponto de vista da qualidade e da segurança no financiamento; ainda que (a respeito dos 
produtores) seus preços de venda sejam excessivamente altos. Várias destas companhias começaram a exportar aos paises industrializados e aos paises latino-americanos sem usufruir das preferéncias comerciais. As grandes emprêsas, como as pequenas companhias locais, costumam ser emprêsas familiares, mas adotaram com êxito as técnicas de organização e a conduta dos administradores profissionais. Os proprietários que administram suas próprias firmas costumam ser importantes líderes do setor privado brasileiro, porque dirigem uma das maiores e mais produtivas emprêsas do Brasil. Os líderes do setor fornecedor adotaram oficialmente a posição de ser conveniente a integração regional da indústria automotriz e que se deveria tratar de conseguir isto. Sem dúvida, têm sérias restriçōes quanto à forma pela qual a integração afetaria o setor privado do Brasil e acreditam que ainda não se pensou nas restrições e proteções adequadas que permitiriam pôr em prática um acôrdo de complementação. A restrição básica é que as possibilidades de concorrência entre as emprêsas estrangeiras (extranacionais) e de emprêsas locais são tão desiguais que a maior concorrência de um mercado regional mais amplo prejudicaria as possibilidades de sobrevivência de muitas emprêsas brasileiras, e seria contrária ao interésse básico do Brasil de estimular um setor privado forte. Em particular, a criação de um mercado regional poderia conduzir à desnacionalizaçăo por duas razōes: primeiro, os produto. res teriam mais possibilidades de fazer economias internas e tenderiam a aumentar 0 seu grau de integração vertical; segundo, poderiam entrar no mercado novos fornecedores estrangeiros ou poderiam ajudar aos fornecedores estrangeiros atuais que acrescentassem novas linhas de produtos. Ainda que a maioria dos fornecedores brasileiros esteja cumprindo muito bem seu papel atualmente, - grau de diversificação é limitado inclusive nas grandes companhias $\theta$ são escassos os recursos técnicos e administrativos. É provável que sua capacidade de introduzir inova- çōes com rapidez como reação ante a concorréncia do comércio exterior seja menor que a de seus concorrentes controlados por interêsses estrangeiros. Tomando as restriçōes formuladas com relação à concorréncia com organizações extranacionais, a maioria dos fornecedores acredita que poderia competir quanto ao preço e qualidade com qualquer emprêsa latino-americana. A aceitação da integração regional parece depender da neutralização da concorrência desigual entre as organizações estrangeiras $\theta$ nacionais no que se refere à produção de peças.

\subsection{O Govêrno}

$A$ indústria automotriz constitui um dos símbolos mais importantes do crescente dinamismo que caracterizou a indústria brasileira nos últimos vinte anos. A indústria permite obter divisas, proporciona emprêgo, difunde a nova tecnologia, aumenta a autonomia nacional, é um exemplo que confirma a tese de que o Brasil "é capaz de conseguir aquilo a que se propóe".

A sugestão de que se deveria reduzir o índice de nacionalização obrigatório para aumentar a eficiência é recebida com ceticismo: com um vasto mercado nacional e uma indústria que tem crescido a um ritmo de cérca de $15 \%$ no último decénio, "para que partilhar ao mercado com outros"? De certa maneira, o público em geral pensa assim, os circulos oficiais $\theta$ inclusive os diretores das indústrias que se encarregam de aplicar as políticas das emprésas que favorecem a integração regional. Parece evidente que no caso brasileiro a integração regional consiste em obter bons resultados e não em salvar uma indústria da saturação do mercado, ou estabelecer as condiçōes mínimas para que essa indústria exista. Acolher-se-iam com agrado as exportações da indústria automotriz, pois contribuiriam para resolver 0 problema do estrangulamento de divisas, mas há pouca motivação para fazé-lo em lugar 
Tabela 2: Principais Países Produtores de Veículos Automotores - 1968/a

(Milhares de unidades)

\begin{tabular}{|c|c|c|c|c|c|}
\hline & País & Total & $\begin{array}{l}\text { Auto- } \\
\text { móveis }\end{array}$ & $\begin{array}{l}\text { Cami- } \\
\text { nhoes }\end{array}$ & Onibus \\
\hline $\begin{array}{l}1 . \\
2 .\end{array}$ & $\begin{array}{l}\text { Estados Unidos } \\
\text { Japäo }\end{array}$ & $\begin{array}{r}10.809 \\
4.086\end{array}$ & $\begin{array}{l}8.848 \\
2.056\end{array}$ & $\begin{array}{l}1.961 \\
1.991\end{array}$ & 39 \\
\hline 3 & $\begin{array}{l}\text { Alemanha } \\
\text { (Reoública Federal) }\end{array}$ & 3107 & 2.862 & 234 & 11 \\
\hline 4. & Reino Unido & 2.225 & 1.816 & 391 & 19 \\
\hline 5. & Franca & 2.076 & 1.833 & 240 & 3 \\
\hline 6. & Itália & 1.664 & 1.545 & 115 & 3 \\
\hline 7. & Canadá & 1.180 & 901 & 276 & 4 \\
\hline 8. & Bélgica & 632 & 605 & 26 & 1 \\
\hline 9 & Austrália & 418 & 346 & 71 & 0.5 \\
\hline 10. & Espanha & 365 & 276 & 85 & 3 \\
\hline & Bras:I & 280 & 210 & 64 & 6 \\
\hline & Suécia & 245 & 223 & 20 & 2 \\
\hline 13 & Africa do Sul & 194 & 143 & 48 & \\
\hline 14. & Argentina & 181 & 128 & 51 & 2 \\
\hline 15 & México & 144 & 103 & 41 & b \\
\hline
\end{tabular}

Fonte: Automotive industrles, julho de 1969, p. 64.

a Em 1968 a produçăo total dos paises da Europa Oriental era: URSS, 801; Alemanha Oriental: năo se dispunha de cifras; Checoslováquia, 150; Polônia, 80; lugosłávia, 72.

b A produçāo de ónibus se Inclul na citra correspondente aos caminhöes. dessas exportações que sòmente aumentariam a concorrência que enfrentam os produtores brasileiros atualmente.

Afora a satisfaçāo, em parte justificada, pelos rendimentos da indústria automotriz na atualidade, muitos funcionários do govêrno têm realmente interêsse em reduzir os elevados custos da indústria. Os produtores sugeriram duas políticas que poderiam contribuir para a reduçāo dos custos: 1) aumentar - volume mediante uma reduçāo tributária (que atualmente representa mais de $40 \%$ do preço de venda, pelo menos dos veículos para passageiros) e 2) aumentar a especialização e a concorrência, diminuindo a proteção. Em ambos os casos se supōe que se fariam economias de escala se aumentasse o volume, e que é alta a elasticidade - preço da demanda de veículos no Brasil. Se existem economias de escala, e se é alta a elasticidade da demanda, as reduções a curto prazo das receitas governamentais devido à redução tri-

GRAFICO UI

Brasil; Orgaion que Participam na Adochto de Deciebos que Afetam I Indireria Automocriz

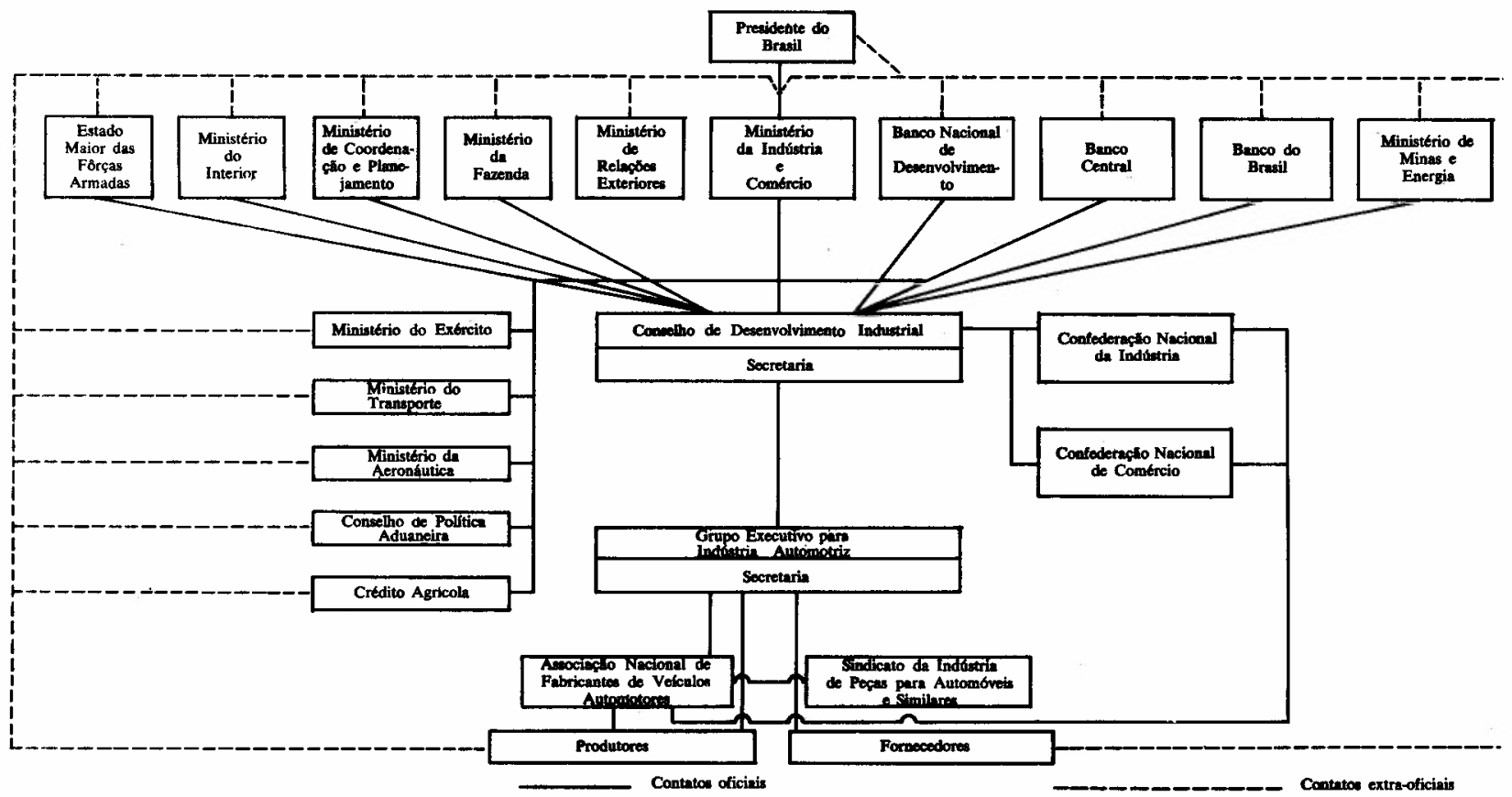


butária, ou o fato de partilhar as novas inversões e o nôvo emprégo com o país com que se comercia, contribuiriam para aumentar a longo prazo as entradas tributárias, a produção, a inversão e o emprégo na indústria automotriz. Se não existem economias de escala não aproveitadas, ou se não é elevada a elasticidade de demanda, a diminuição dos impostos ou o aumento do comércio beneficiaria provàvelmente aos interêsses especificos da indústria (inclusive muitas emprésas estrangeiras), mas não os interêsses gerais do Brasil. No que se refere a escolher entre reduções tributárias e diminuição da proteção, a segunda medida tem a vantagem de permitir ao govêrno manter a tributação atual e de qualquer maneira conseguir reduzir os custos e aumentar o volume da fabricaçăo de veículos. ${ }^{7}$

Os argumentos não económicos contrários à integração regional continuarão influindo na medida em que não se obtenham os dados económicos reais sôbre as economias de escala e a elasticidade da demanda. Nestes argumentos considera-se o contrôle nacional na adoção de decisões, na elevação ao máximo da capacidade de defesa nacional, na proteção do espírito de emprésa nacional, e no desejo de evitar interferéncias com os objetivos da politica estrangeira geral.

No gráfico 2 se apresentam os diversos ministérios e organismos que participam da formulação da política automotriz. Os propositores da integração expressaram ao autor que a autoridade decisória em matéria de acórdos de complementação da indústria automotriz $e$ indefinida ou difusa até o ponto que se torna muito frustrante fomentar esses acôrdos. Talvez o que pareça ser um problema de complicação burocrática năo seja mais que um reflexo da falta de argumentos económicos convincentes da parte dos que propōem a integração.

7 Outra vantagem importante seria a criaçăo de economias externas em outros setores com boas perspectivas de exportação, através do aperfeiçoamento da infra-estrutura de exportaçăo.

Janeiro/Marso 1971

\section{Conclusões: recomendaçőes politicas}

Além do apoio retórico a favor da conveniência e dos beneficios potenciais da integração regional da indústria automotriz, pouco se avançou para a sua realização. A integraçăo que existe costuma ser bilateral entre dois paises, um grande e outro pequeno, que comerciam, e são tantas as restrições e limitações estabelecidas que os efeitos da especializaçăo sôbre os custos são reduzidos. E necessário adotar duas medidas para tornar realidade a integração regional: primeiro, é necessário averiguar as razōes pelas quais os custos da indústria automotriz latino-americana são altos, e sobretudo qual é a importância real das economias de escala, e segundo, as instituiçőes que se interessam peta integração devem encontrar uma solução de acôrdo para conciliar de forma criativa seus pontos de vista divergentes. A análise a fundo dos custos ultrapassa os alcances dêste trabalho. Suponho que as economias de escala sejam um dos fatóres importantes que explicam os niveis de custo, e que um programa de integração regional seja um meio para consegui-los, em seguida indicam-se várias modificações para a política das instituiçōes respectivas. Seu objetivo é explicar algumas maneiras de transformar o vago consenso geral em programas práticos.

\subsection{Os Produtores}

Sugere-se que se dẻ maior importância à planificação coordenada das atividades regionais, especialmente no que se refere ao desenho e especificação do produto, e aos investimentos. Além disso, deveriam divulgar melhor nos governos as bases econômicas que justificam a integração regional. Como medida prática, seria útil preparar projetos mais concretos de integração e proposiçőes mais concretas de intercåmbio e submetê-los à consideração dos governos.

Várias medidas poderiam contribuir para resolver a controvérsia entre o capital na- 
cional e o estrangeiro. Poderia dar-se a emprêsas fornecedoras nacionais capital estrangeiro e local: 1) ajuda especial para o comércio das exportaçōes, tanto no mercado regional como nos paises industriais; 2) oferecerse-iam sugestões aos governos e às associaçōes comerciais respectivas sôbre as fusões benéficas para os fornecedores locais; 3) deveriam continuar a intensificar-se os esforços gerais para aumentar a capacidade dos fornecedores. Finalmente, haveria que considerar sèriamente a possibilidade de dar aos investidores locais a oportunidade de investir no capital das emprêsas produtoras controladas por interêsses estrangeiros, possivelmente mais sôbre uma base regional que por paises.

\subsection{Os Fornecedores Controlados Por Interêsses Estrangeiros.}

A modificação dos acôrdos de autorização que restringem o comércio para a exportação constituiria uma medida muito positiva. Outro passo útil seria a redução gradual da duplicação dos investimentos na região e a aplicação de políticas de investimento que se ajustem melhor.

\subsection{Fornecedores Controlados Por Interêsses Nacionais.}

A modificação fundamental da poilitica dos fornecedores controlados localmente seria mostrarem-se mais favoráveis à fusão com outros fornecedores a fim de criar emprêsas mais poderosas e diversificadas. Isto contribuiria para o melhoramento da capacidade empresarial, de maneira que possam encarar os problemas que suscita o comércio das exportações e o ajuste à maior concorrência.

\subsection{Os Governos}

E indispensável que os governos da América Latina considerem a economia em seu conjunto em lugar de cada setor separa- damente. Isto levaria a reconhecer a conveniência de coordenar suas políticas para a indústria automotriz a fim de obter os beneficios económicos da especialização. Embora a política dêste setor tivesse que ser mais interdependente com a de outros paises, aumentaria a auto-suficiência nacional geral devido ao aumento da produtividade. Ao diminuir os recursos absorvidos pela indústria automotriz, aumentarão os recursos disponíveis para outros setores.

Também se sugerem as seguintes políticas governamentais de complementação: 1) criar um fundo de reorientação para os operários e as indústrias, as quais a expansão do comércio haja afetado desfavoràvelmente; 2) estabelecer incentivos para estimular a fusão entre os fornecedores tanto nacionais quanto internacionais; 3) estabelecer uma comissão internacional para controlar a produção e a inversão regionais na indústria automotriz; 4) cooperar com as companhias estrangeiras na definição de mecanismos práticos que permitam o acesso dos investidores locais ao seu capital; e 5) criar a infra-estrutura que facilite o comércio, e que inclui desde as instalações portuárias e as estradas até os programas de capacitação em técnicas de exportação.

As modificações gerais assinaladas na política se reforçam reciprocamente. Ao pôlas em prática poderá transformar-se a crescente concorrência entre a indústria automobilistica dos países da América Latina e sua falta de coordenação em um crescimento cooperativo a longo prazo, baseado no aumento da produtividade. Caberia esperar que essas medidas se traduzam na criação de indústrias em cada um dos países-membros que sejam capazes de competir nos mercados internacionais em um pé de igualdade. A longo prazo, sómente as políticas que capacitem os paises a participar plenamente e em condições de igualdade na economia mundial permitir-lhesão resolver as possiveis discrepâncias que se produzam entre suas ambiçōes nacionais e a interdependência econômica mundial. 